\title{
Sleep Quality and Anxiety in Different Sports Categories
}

\section{Franco $\mathbf{L}^{1 *} \mid$ Solis $\mathbf{M}^{2} \mid$ Rodriguez $\mathbf{A B}^{2} \mid$ Terrón $\mathbf{M P}^{1}$}

*Correspondence: Lourdes Franco Hernandez

Address: ${ }^{1}$ Faculty of Medicine, University of Extremadura, Badajoz, Spain; ${ }^{2}$ Faculty of Science, University of Extremadura, Badajoz, Spain

e-mail $\bowtie$ : lourdesfh@unex.es

Received: 23 June 2021; Accepted: 29 June 2021

Copyright: (C) 2021 Franco L. This is an open-access article distributed under the terms of the Creative Commons Attribution License, which permits unrestricted use, distribution, and reproduction in any medium, provided that the original work is properly cited.

\section{ABSTRACT}

Sleep is a needed and repairing physiological state, usually recurring and reversible, characterized by a depression in the senses, the conscience, and the spontaneous motricity, in which a person can awaken due to sensory stimulus. In the case of athletes, sleep has been considered a key factor for competition and its efficiency, being the most common alterations among athletes partial sleep privation and fragmented sleep. athletes increase their anxiety level when the competition is approaching. This increase in anxiety produces a negative effect in the sleep quality, motivating a sleep disruption before a competition. We selected volunteers of 4 kinds of sports: athletics, boxing, basketball and crossfit and a control group was added that didn't practice any sports with regularity. All the participating filled the State-Trait Anxiety Inventory (STAI) and the Pittsburgh Sleep Quality (PSQI) tests. This sleep is affected by the stress athletes are subjected to before a competition. Anxiety shows higher levels in women than in men, so women are worse sleepers than men.

Keywords: Anxiety, Athletics, Sleep, Sport

\section{Introduction}

Humans have the physiological necessity of sleeping throughout their lives to recover the energy they have lost in their daily lives activities, and therefore, keeping healthy (Fernández et al., 2003; Caia et al., 2017). When we are sleeping, our vital functions remain, although more slowly, and our energy requirement is lower. Therefore sleep is a needed and repairing physiological state, usually recurring and reversible, characterized by a depression in the senses, the conscience, and the spontaneous motricity (Houssay, 2000), in which a person can awaken due to sensory stimulus (Guyton and Hall, 2001). The recommendation is to sleep between 7-9 hours during the night (Hirshkowitz et al., 2015) but in athletic people it should be between 9-10 hours of sleep during the night (Bird, 2013). However a lot of disturbances can affect sleep, among the more frequent are: somnolence, tiredness, sleeplessness and the disruption of sleep-awake rhythms (Walsleben, 1982). This disorder appears in the 12- $25 \%$ of the general population (Walsleben, 1982), and frequently is connected to stress in any situation, like illness, ageing and pharmacology treatment. 
Sleep quality is, therefore, a great important clinical aspect and it's shown in the statistics that confirms that $30-40 \%$ of the population has insomnia, and $60 \%$ of shift workers reported disruptions in the wake-sleep cycles (American Psychiatric Association, 1994). In this way, the subjective measuring, psychological screening like clinic interviews, scales and sleep questionnaires, and shelf-records, try to measure different parameters involved in the sleep act and in the consequences of the lack of sleep. Therefore, evaluations of sleep scales through shelf-records were developed. This kind of evaluation is basically subjective and includes quantitative aspects like sleep duration, number of wake ups, sleep latency, and qualitative aspects like sleep feeling, mood or the sleep contents (Buysse et al., 1989).

In the case of athletes, sleep has been considered a key factor for competition and its efficiency (García-Mas et al., 2003), being the most common alterations among athletes partial sleep privation and fragmented sleep. Many researches suggests sporty usually sleep worse during competition periods, especially the night before an important competition (Kubitz et al., 1996; Fu Y, 1999) and that the reduction of sleep hours has a negative effect in their performance (Cheikh et al., 2018). Furthermore, athletics increase their anxiety level when the competition is approaching. This increase in anxiety produces a negative effect in the sleep quality, motivating a sleep disruption before a competition (Monti and Monti, 2000). An inadequate sleep will have a negative impact in the training recovery, with a decrease in performance. Hence, sleep is one of the most important recovery strategies for athletes, and those with bad sleep habits could have a higher risk of physical and mental overloading (Malhotra, 2017).

Anxiety is another important factor in sports performance. Athletes have an increase in anxiety before a competition (But et al., 2003). This anxiety isrelated with the time and the location where the event is developed (Cerin, 2003).

In this way, taking into account all these statements, we want to analyze the relation between sleep quality and anxiety before competition in different sport categories and different genders.

\section{Material and Methods}

\section{Design of Investigation}

An experimental study was conducted to determine if a relation between the practices of different sports activities, sleep quality and anxiety levels exists. We selected volunteers of 4 kinds of sports: athletics, boxing, basketball and crossfit and a control group was added that didn't practice any sports with regularity. These sports were widely practiced in our city during the recollection of data for this study. 


\section{Volunteers}

A total of 83 athletes ( 42 men and 41 women), who volunteered after an informative talk. Exclusion criteria were based in volunteers without previous physical or psychological pathologies volunteered to participate in the study. All of them belong to a federate sports team from Extremadura. The data of the individuals were $17-33(=23,37 \pm 3,85)$ years old. The volunteers under 18 had to fill a document signed by their parents or tutor. In Table 1 it is shown the description of our sample (Table 1).

Table 1: General Sample Description

\begin{tabular}{|l|l|l|l|l|}
\hline Speciality & Athletes & $\%$ & Woman & Men \\
\hline Athletism & 19 & 18,09 & 9 & 10 \\
\hline Boxing & 21 & 20 & 9 & 12 \\
\hline Crossfit & 24 & 22,85 & 11 & 13 \\
\hline Basketball & 19 & 18,09 & 12 & 7 \\
\hline Control group & 22 & 20,95 & 11 & 11 \\
\hline Total & 105 & & $52(49,5 \%)$ & $53(50.5 \%)$ \\
\hline
\end{tabular}

\section{Questionnaire}

Self-made questionnaires were filled from March 2019 to May 2019. In this time, the professional athletes were under the same condition of stress because they were at the end of the tournaments season. All the participating filled the State-Trait Anxiety Inventory (STAI) (Spielberger et al., 2008) and the Pittsburgh Sleep Quality (PSQI) (Buysse et al., 1989) tests.

The anxiety level was analyzed by STAI questionnaire which has different self-evaluated scales measuring 2 independent concepts: Anxiety-State (AE) and Anxiety-Range (AR) (Spielberger et al., 2008). The second scale of this study was the only one that was taken into consideration because this shows us the anxiety propension, which is stable and it is the ability of a person to notice threatening situations. In athletes in a high Anxiety-Range state, they would be in a threat or alert state during competition.

With the Pittsburgh Sleep Quality Index (PSQI) (Buysse et al., 1989), we measured the subjective sleep quality. This questionnaire has 19 items that determine the sleep parameters, sleep duration, sleep disturbance, sleep quality, daytime dysfunction, sleep latency and the Indicator of Sleep Quality (IPCS) (Buysse et al., 1989). We discard the parameter of medication use because our participants don't take any. All the questions of the test are from the last month of the volunteer's life. The score of these seven parameters are between 0 (it doesn't exist difficulty), to 3 (serious difficulty). The global score has a rank between 0 (no difficulty) to 21 (difficulty in all components that can be measured in this test). 
The volunteers were asked to complete the questionnaire carefully and to spend the necessary time to fill it.

\section{Statistical Analysis}

A descriptive study was conducted, measuring qualitative variables of the medium and standard deviation $(\mathrm{X} \pm \mathrm{DS})$.

The descriptive and inferential study was conducted with the GraphPadPrism6 software for the statistical resolution. It was verified with the Kolmogorov-Smirnov test, if the population were in a normal distribution. The results were analyzed with ANOVA variance tests between the comparison of multiple and well-balanced groups. The significance was $0,05(\mathrm{p}<0,05)$.

\section{Results}

\section{The Pittsburgh Sleep Quality Index}

The data obtained in the Pittsburgh Sleep Quality Index it's shown in Table 2. To ease the comprehension of the results, you can only see the items of the test with significant differences.

Table 2: Medium Value obtained in each kind of sport after filling the Pittsburgh Sleep Quality Index. M=Men, W=Woman. a) pvalue $<0,05$ respect to the control; b) p-value $<0,05$ respect to the opposite gender in the same kind of sport

\begin{tabular}{|c|c|c|c|c|c|c|c|c|c|c|}
\hline & & & \multicolumn{4}{|c|}{ Endurance Sports } & \multicolumn{4}{|c|}{ Intermittent Sports } \\
\hline & \multicolumn{2}{|c|}{ Control } & \multicolumn{2}{|c|}{ Athletism } & \multicolumn{2}{|c|}{ Crossfit } & \multicolumn{2}{|c|}{ Basketball } & \multicolumn{2}{|c|}{ Boxing } \\
\hline & M & W & M & W & M & W & $\mathrm{M}$ & W & M & W \\
\hline Sleep duration & $0 \pm 0$ & $\begin{array}{l}0,27 \pm \\
0,46 b\end{array}$ & $0 \pm 0$ & $\begin{array}{l}0,88 \pm \\
0,78 b\end{array}$ & $\begin{array}{l}1,16 \pm \\
0,42 b\end{array}$ & $\begin{array}{l}0,63 \pm \\
0,50\end{array}$ & $\begin{array}{l}0,71 \pm \\
0,48\end{array}$ & $\begin{array}{l}0,5 \pm \\
0,52\end{array}$ & $\begin{array}{l}0,66 \pm \\
0,46 a\end{array}$ & $1 \pm 0 \mathrm{~b}$ \\
\hline Sleepdisturbance & $\begin{array}{l}0,36 \pm \\
0,67\end{array}$ & $\begin{array}{l}0,90 \pm \\
0,83\end{array}$ & $\begin{array}{l}1 \pm \\
0,63\end{array}$ & $\begin{array}{l}0,66 \pm \\
0,86\end{array}$ & $\begin{array}{l}1,46 \pm \\
0,87 a\end{array}$ & $\begin{array}{l}2 \pm 1 \\
a, b\end{array}$ & $\begin{array}{l}1,14 \pm \\
0,69\end{array}$ & $\begin{array}{l}1,75 \pm \\
1,05 b\end{array}$ & $\begin{array}{l}0,16 \pm \\
0,38\end{array}$ & $\begin{array}{l}0,33 \pm \\
0,5\end{array}$ \\
\hline Sleepquality & $0 \pm 0$ & $\begin{array}{l}1,09 \pm \\
0,30 a\end{array}$ & $\begin{array}{l}0,4 \pm \\
0,51 \mathrm{a}\end{array}$ & $\begin{array}{l}1,11 \pm \\
0,60 b\end{array}$ & $\begin{array}{l}0,84 \pm \\
0,68 \mathrm{a}\end{array}$ & $\begin{array}{l}1,45 \pm \\
0,68 a b\end{array}$ & $\begin{array}{l}0,85 \pm \\
0,37\end{array}$ & $\begin{array}{l}1,25 \pm \\
0,62 \mathrm{ab}\end{array}$ & $\begin{array}{l}0,75 \pm \\
0,75 a\end{array}$ & $\begin{array}{l}0,66 \pm \\
0,5 a\end{array}$ \\
\hline Daytimedysfunction & $\begin{array}{l}0,45 \pm \\
0,52\end{array}$ & $\begin{array}{l}0,81 \pm \\
0,98\end{array}$ & $\begin{array}{l}1,4 \pm \\
0,51\end{array}$ & $\begin{array}{l}1,33 \pm \\
0,5\end{array}$ & $\begin{array}{l}1,07 \pm \\
0,95 \mathrm{f}\end{array}$ & $\begin{array}{l}1,25 \pm \\
0,96\end{array}$ & $\begin{array}{l}0,71 \pm \\
0,75\end{array}$ & $\begin{array}{l}0,58 \pm \\
0,79\end{array}$ & $\begin{array}{l}0,25 \pm \\
0,45 \mathrm{~cd}\end{array}$ & $0 \pm 0 \mathrm{~cd}$ \\
\hline Sleeplatency & $\begin{array}{l}0,45 \pm \\
0,68\end{array}$ & $\begin{array}{l}2,18 \pm \\
0,40\end{array}$ & $\begin{array}{l}1,6 \pm \\
0,69 a\end{array}$ & $\begin{array}{l}1,33 \pm \\
0,70\end{array}$ & $\begin{array}{l}1,92 \pm \\
0,64\end{array}$ & $\begin{array}{l}1,90 \pm \\
0,83\end{array}$ & $\begin{array}{l}2,12 \pm \\
0,99\end{array}$ & $1 \pm 0,60$ & $\begin{array}{l}2,58 \pm \\
0,51 a b\end{array}$ & $1 \pm 0,86$ \\
\hline PSQI & $\begin{array}{l}3,18 \pm \\
1,94\end{array}$ & $\begin{array}{l}7,09 \pm \\
2,77\end{array}$ & $\begin{array}{l}4,9 \pm \\
2,02\end{array}$ & $\begin{array}{l}5,44 \pm \\
1,74\end{array}$ & $\begin{array}{l}6,38 \pm \\
2,66 a\end{array}$ & $\begin{array}{l}7,45 \pm \\
4,32 \mathrm{a}\end{array}$ & $\begin{array}{l}6 \pm \\
2,17 a\end{array}$ & $\begin{array}{l}6,28 \pm \\
1,70 \mathrm{a}\end{array}$ & $4 \pm 0,86$ & $\begin{array}{l}4,16 \pm \\
2,62 \mathrm{a}\end{array}$ \\
\hline
\end{tabular}

To summarize, we dichotomized the groups in good sleepers (PSQI<5) and poor sleepers (PSQI $>5$ ) (Agargun et al., 1996). The data appears in Table 3. 
Table 3: Dicotomitation of good sleepers and poor sleepers according to score in the PSQI

\begin{tabular}{|l|l|l|l|}
\hline \multicolumn{2}{|c}{ Good Sleepers } & \multicolumn{2}{c|}{ Poor Sleepers } \\
\hline Control F & $7,09 \pm 2,77$ & Control M & $3,18 \pm 1,94$ \\
\hline Athletics F & $5,44 \pm 1,74$ & Athletics M & $4,9 \pm 2,02$ \\
\hline Crossfit M & $6,38 \pm 2,66$ & Boxing M & $4 \pm 0,86$ \\
\hline Crossfit F & $7,45 \pm 4,32$ & Boxing F & $4,16 \pm 2,62$ \\
\hline Basketball M & $6 \pm 2,17$ & & \\
\hline Basketball F & $6,28 \pm 1,70$ & & \\
\hline
\end{tabular}

The results in the Anxiety Range test (AR) are represented according to gender. In this way, in Fig. 1 , we see the values of the masculine group, discovering that between the control group and the other male groups there is a significant difference, a higher Anxiety Range in the control group than in the rest of groups. It wasn't found any significant difference among the different sports. The lowest Anxiety Range level was found in the Crossfit Male group.

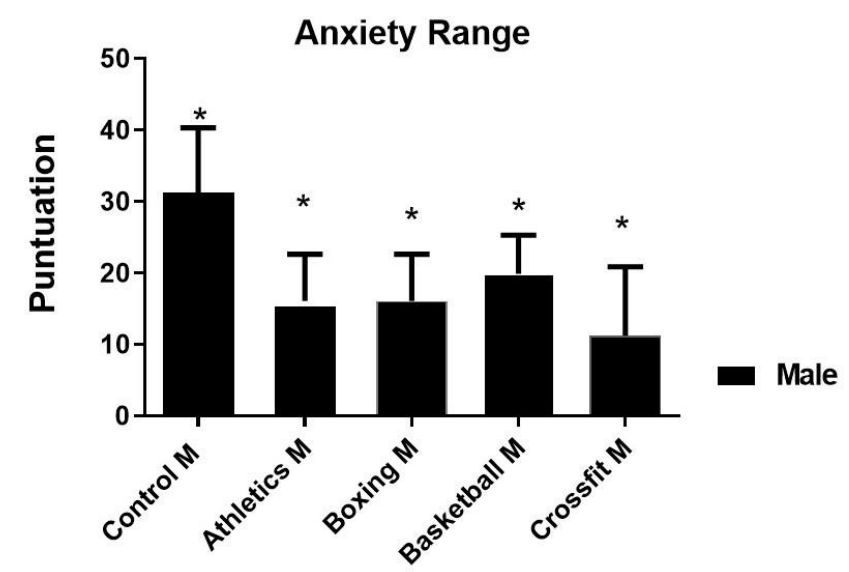

Figure 1: Represents the Anxiety/Range levels (AR) in men (M) in the different sport groups. $( \pm \mathrm{SD}) .\left({ }^{*}\right) \mathrm{P}$-valor $<0,05$ respect to Control M

\section{Anxiety Range}

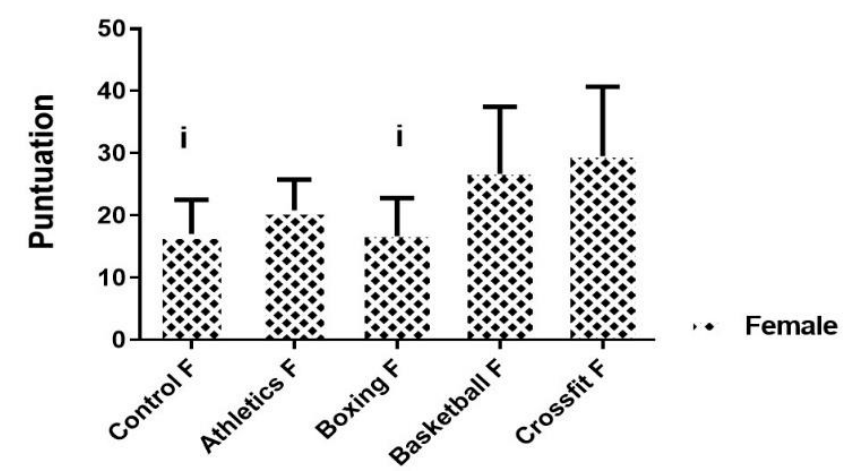

Figure 2: Represents the Anxiety/Range levels (AR) in women (W) in control and the different sport groups. ( \pm SD). (i) Pvalor $<0,05$ respect to Crossfit $F$ 


\section{Ratio PSQI-A/R}

In Fig. 3 we can see the relation between the PSQI values and the Anxiety Range (AR) medium values. In all the analyzed groups, there were higher values in the indicator of total quality sleep (PSQI), more in the femenin gender than in the masculine groups, so women had worse sleep quality than men. In addition, these PSQI high values are associated with high values in AR. And vice versa, low values in PSQI indicates better sleep quality are associated with lower values of Anxiety Range.

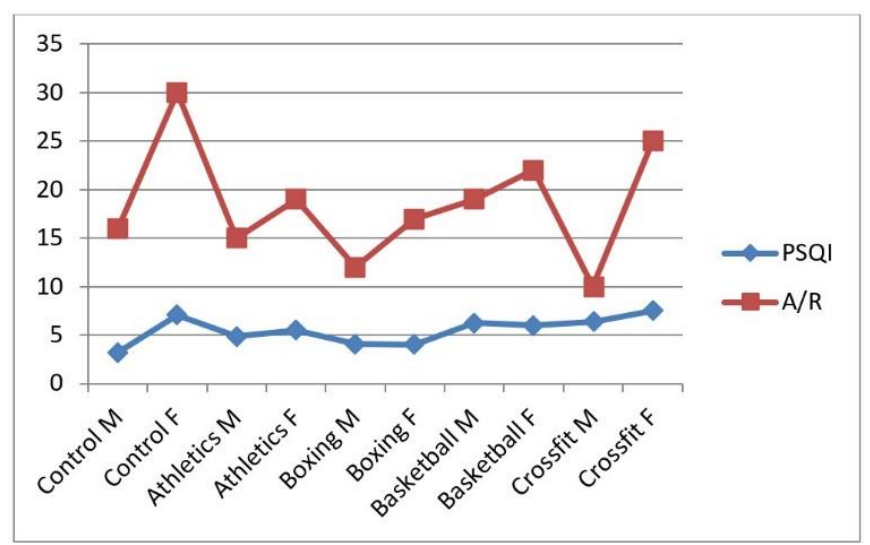

Figure 3: Represents medium values obtained in the PSQI global indicator of sleep and medium values obtained in AR

\section{Discussion}

Analyzing the duration of sleep, we can see that boxing and athletics are lower than control group. Sleep disorders are greater in crossfit volunteers regarding control group. The lack of sleep affects important aspects in the practice of different sports disciplines, like speed, stamina, attention, executive function and learning (Simpson et al., 2017). Besides, stamina sports are more affected by the lack of sleep than strength sports. Sleep helps restore the immune system and muscular and cartilage recovery after an intense training (Kirschen et al., 2018).

The second aim of this study was to investigate the temporal relationship between state anxiety and changes in precompetitive sleep quality. Athletes worrying about the competition appear to start worrying about their sleep as well. Furthermore, it is these changes in cognitive anxiety that are negatively related to changes in perceptions of the restorative value of sleep. As we have seen in other articles, this anxiety is related to with the hour of the day and the place where the event is developed (Cerin, 2003).

In the table of the dichotomic separation we can see that the majority of the bad sleepers are women, because they have more basal anxiety, so we can think that these results are expected according to the bibliography where Krane V and Williams JM, (1987) determined that when there is a sport 
competition, the man has lower levels of anxiety. In spite of this, according to other authors (Jones and Swain, 1992), we have to evaluate the psychosomatic cognitive interpretation that each athlete has because some of them are comfortable with high levels of anxiety, and improving their competition results.

These bad sleeper results were also found by Swinbourne R, Gill N, in 2016. They developed a studio with 175 men and women athletes and they observed that $50 \%$ of athletes are well sleepers. Moreover, they found that they have $28 \%$ somnolence, which is clinically meaningful. One of the factors of this worse quality is related to the higher sleep latency in athletes (Leeder et al., 2012).

Also, in our study differences in sleep latency and efficiency appearedwhich are the same results as Lastella, et al. (2015) who analyzed sleep in 124 elite athletes, in individual and group sports where it was observed a $86 \%$ of sleep efficiency, lower in individual sports than in group sports. So, with our study we can conclude that athletes in individual sports have more anxiety than group sports. It can be caused by responsibility falling only in one individual. Because of this, there are some authors (Saez, 2017) who incise in the importance of psychological work and self-confidence as a fundamental skill in competitive athletes, so self-esteem can improve sport efficiency, influencing their anxiety and their night sleep. The limitations of the study are that they were conducted in a period of time with a specific photoperiod conditions and these conditions varies throughout the year and this can affect the sleep quality.

\section{Conclusion}

Respect to the Pittsburgh Sleep Quality Index, we can say that men and women that practice crossfit and basketball, and the women that practice boxing, have a worse sleep quality in comparison to people that don't practice sports professionally.

Following the dichotomic criteria of good and bad sleepers, the poor sleepers groups are mostly women.

After analyzing the anxiety, the most interesting conclusion is in the crossfit results. Men that practice crossfit are the ones with less anxiety. However, women that practice crossfit presents higher levels of anxiety.

Sleep is important for the sport development and efficiency. This sleep is affected by the stress athletes are subjected to before a competition. Anxiety shows higher levels in women than in men, so women are worse sleepers than men. 


\section{References}

Agargun MY, Kara H, Anlar O. The reliability and validity the Pittsburgh sleep quality index. Turkish Journal of Psychiatry 1996; 7: 107-111.

American Psychiatric Association. Diagnostic and Statistical Manual of Mental Disorders. (4a ed). Washington, EEUU: American PsychiatricAssociation, 1994.

Bird SP. Sleep, recovery, and athletic performance: A brief review and recommendations. Strength and Conditioning Journal 2013; 35: 43-47.

But J, Weimnberg R, Horn T. The Intensity and Directional Interpretation of Anxiety: Fluctuations Throughout Competition and Relationship to Performance March Sport Psychologist 2003; 17: 35-54.

Buysse DJ, Reynolds CF, Monk TH, Berman SR, Kupfer DJ. The Pittsburgh Sleep Quality Index: a new instrument for psychiatric practice and research 1989; 28: 193-213.

Caia J, Halson SL, Scott TJ, Kelly VG. Intra-individual variability in the sleep of senior and junior rugby league athletes during the competitive season. Chronobiology International 2017; 34: 1239-1247.

Cerin E. Anxiety versus fundamental emotions as predictors of perceived functionality of pre-competitive emotional states, threat, and challenge in individual sports. Journal of Applied Sport Psychology. Taylor \& Francis Sáez G 2003; 15 : 223-238.

Cheikh M, Hammouda O, Gaamouri N, Driss T, Chamari K, Cheikh RB, Souissi N. Melatonin ingestion after exhaustive lateevening exercise improves sleep quality and quantity, and short-term performances in teenage athletes. Chiatry Res 2018; 28: 193-213.

Fernández Ferrin C, Garrido Abejar M, Santo Tomas Pérez M, Serrano Parra MD (2004) Enfermería Fundamental. Barcelona, Masson, ISBN:978-84-458-1355-3.

Fu Y (1999) Current research sitiation of sports insomnia. Journal of Chengdu Physical Education Institute 25: 56-60.

García-Mas A, Aguado FJ, Cuartero J, Calabria E, Jimenez R, Pérez P. Revista Española de Psicología del Deporte 2003; 12 : 181-195.

Guyton AC and Hall G. Tratado de Fisiología Médica (2001) 10a Ed. McGraw-Hill - Interamericana, Madrid.

Hirshkowitz M, Whiton K, Albert SM, Alessi C, Bruni O, DonCarlos L, AdamsHillard PJ. National sleep foundation's sleep time duration recommendations: Methodology and results summary. Sleep Health 2015; 1: 40-43.

Houssay Cingolani Horacio E. Fisiología Humana. (2000) 7a. Ed. El Ateneo 812-815.

Jones G and Swain A. Intensity and di- rection dimensions of competitive state anxiety and relationships with competitiveness. Perceptual and Motor Skills 1992; 74: 467-472.

Kirschen GW, Jones JJ, Hale L. The Impact of Sleep Duration on Performance Among Competitive Athletes:A systematic literature review. Clinical Journal of Sport Medicine 2020; 30: 503-512.

Krane V and Williams JM. Cambios en el rendimiento y la ansiedad somática y de confianza antes de la competición. Diario de Comportamiento Deporte 1987; 10: 47-56.

Kubitz KA, Landers DM, Petruzzello SJ, Han H. The effects of acute and chronic exercise on sleep. A meta-analytic review. Meta-Analysis Sports Med 1996; 21: 277-291. 
Lastella M, Roach GD, Halson SL, Sargent C. Sleep/wake behaviours of elite athletes from individual and team sports. European Journal of Sport Science 2015; 15: 94-100.

Leeder J, Glaister M, Pizzoferro K, Dawson J, Pedlar C. Sleep duration and quality in elite athletes measured using wristwatch actigraphy. Journal of Sports Sciences 2012; 30: 541-545.

Malhotra R. Sleep, recovery, and performance in sports. Neurological Clinical 2017; 35: 547-557.

Monti JM and Monti D. Sleep disturbance in generalized anxiety disorder and its treatment. Sleep Med Rev 2000; 4: 263276.

Sáez G. Interpretación de la táctica predominante del adversario. Revista Peruana deficiencias del ejercicio físico 2016; 44: 23.

Simpson NS, Gibbs EL, Matheson GO. Optimizing sleep to maximize performance: implications and recommendations for elite athletes. Scandinavian Journal of medicine \& Science in Sports 2017; 27: 266-274.

Spielberger CD, Gorsuch RL, Lushene RE (2015) Cuestionario de Ansiedad Estado- Rasgo, C.D. Madrid, ISBN: 978-8416231-15-7.

Swinbourne R, Gill N, Vaile J, Smart D. Prevalence of poor sleep quality, sleepiness and obstructive sleep apnoea risk factors in athletes. European Journal of Sport Science 2016; 16: 850-858.

Walsleben J. Sleep disorders. Am J Nurs 1982; 82: 936-940. 